\title{
Authorities Make too Many Mistakes
}

\author{
HAROLD H. AXTELL, Buffalo Museum of Science, Buffalo, N.Y.
}

Reprinted from The Kingbird, publication of the Federation of New York State Bird Clubs, Vol. V, No. 2, July, 1955

The most competent field ornithologists can misidentify birds on occasion. In other words, man is not perfect and hence may make mistakes. To reduce these errors to a minimum, statisticians and other compilers of sight records, must demand of everyone a written report of the circumstances concerned with an unusual observation. This is necessary so that future authors can evaluate the sight record on the evidence obtained at the time of observation

A frequent source of error is in misjudging size. Several times $f$ have seen perched Starlings mistaken for Crows. Persons who have spent a great deal of time at Hawk Mountain have momentarily mistaken airplanes, butterflies and even gnats for hawks. Usually experienced observers quickly discover their error but on three or four occasions. I have known a distant airplane to remain misidentified long enough for more than one person to express a serious opinion on what kind of hawk it was.

One competent authority I know misidentified a Crow because he was unaware of a size illusion even after some twenty or thirty seconds of discussion and looking at the bird. Finally one of his companions had to tell him that the bird perched in the top of an apple tree 150 yards away, which he persisted in calling a Crow, was in reality a Redpoll!

Another frequent source of error is color illusion. Two widely recognized authorities whose records are almost never doubted agreed that two birds were definitely swans, and wrote them down as such on their field record sheet. It then occurred to them to try to determine which kind of swan. They approached closer, and to their astonishment found their "swans" to be Black Ducks. Light conditions can perform apparent miracles in creating il- lusions of many kinds, especially of color. Many birders have known a "big white bird" to turn out to be a normally colored Crow.

It is generally stated (and to some extent true) that the validity of a record is greatly increased when several observers concur in its identification. The reader will note, however, that all of the following misidentifications cited here involve several or many observers, including in each instance a number of authorities of some repute. In each instance also, there was no likelihood that the observers were not all referring to the same bird.

Fox Sparrcws had been reported in early September, some weeks earlier than normal, by the local bird authcrity in a small community. The following day six bird birders from elsewhere, three of whom are commonly acceded the status of authorities in their home country, went to verify the report. The three leaders were pointing out several birds 15 to 40 feet away as Fox Sparrows to their three friends, who were concurring, when 2 more bird watchers came along who succeeded in convincing them that the birds were all Song Sparrows. Apparently no Fox Sparrows were present ...

In spite of such occurrences, good observers are not likely to discover how often they may be wrong unless they break up into separate groups, see and identify some of the same birds, then get together and compare notes. This procedure is often so startingly revealing that it might well be tried by clubs as a scientific exercise to prove the need for greater caution, skepticism, and verification. I will restrict my illustration to a single example. Three automobile-loads of us were on a field trip that was notable for the number of experts in each car. A large hawk flew low and slowly over the road while the occupants of all three cars stopped and examined it. A few minutes later we met and discovered that the occupants of one car had unanimously agreed that the hawk was a Red-tail, those of another car agreed it was a Rough-leg, 
and the third a Marsh Hawk

The immediate purpose of this paper is to promote a more widespread recognition of the knowledge that apparently all field students of birds make frequent errors in sight identification of which they often remain unaware. In so far as this immediate purpose is achieved, two further steps should logically follow: first. a popular recognition of the unreliability of sight records as usually compiled, and second, a desire for greater reliability, with an increased in terest in adopting scientific methods of verification.

Birders would then recognize that for an important sight record, there is a lack of adequate authority in any observer's mere reputation or in his avowed feeling of absolute certainty. These fallen authorities . . must then be replaced by the superior authority of permanently available evidence, even if it is only written evidence of the mental processes by which a person determined the identity of a bird. Lacking material evidence such as a specimen, photograph, or sound recording, the person interested in making a valid sight record of a rarity will supply evidence by making a com- plete written record preferably on the spot, that shows all the observations, reasoning, and other factors on which he based his identification. This account should be filed permanently in some known place where it will always be available to any qualified student for reference

It can be examined in detail and used as the basis for a reasoned judgment as to the proboble correctness of the identification.

It should be added that although an observer's birding experience, knowledge, ability, and honesty are not, by themselves alone, sufficient to make his unusual sight records acceptable to a properly informed compiler, these achievements are none-the-less of basic importance. Every ccmpetent censor-compiler learns to look for signs of these characteristics in every verifying account by "leading between the lines," if necessary . . Adoption of these verifying procedures will not give us sight records in which the correctly identified are always distinguishable, with $100 \%$ certainty, from the misidentified. But the improvement in the ability of compilers to judge the probable validity of the records will be enormous.

\section{Christmas Gift Suggestions}

GIVE A BIRD BOOK - A bird book makes an ideal Christmas present, particularly for young people: There are many bird books on the market these days; many are good and some are not so good. However, it should be pointed out that the first essential is a field guide for identifying birds. It is almost universally agreed that by far the best book for this purpose is still R. T. Peterson's Field Guide to the Birds. Again we must caution you NOT to buy the Field Guide to the Western Birds as this covers the Rocky Mountains and beyond. Available at the Canada Drug and Book Store in Regina, at $\$ 4.00$, plus 10 cents allowance for postage.

GIVE THE BLUE JAY - Look back over the 1956 Blue Jays and see how many interesting articles and pictures are contained in one year's membership. Bring pleasure throughout 1957 by giving a membership in our society and a subscription to the Blue Jay to one or more of your friends. Each subscription costs you only $\$ 1.00$.

There are also a limited number of 1956 Blue Jays available. The four numbers of the 1956 issue are being sold for one dollar. They can be sent out together in an envelope to make an excellent gift for Christmas. The 1954 and 1955 Blue Jays (eight issues) are also available for one dollar; all 8 for $\$ 1,00$ or any 4 copies for 50 cents. Since the surplus which we printed in 1954 and 1955 is now considerably reduced, this is positively the last offer at half price. Following this offer, we shall keep a few sets on hand which will then be available at $\$ 1.00$ per set. Make a set of the Blue Jay one of YOUR Christmas gifts this year. Write to Elmer Fox, 1053, Gladmer Park, Regina. 